\title{
BMJ Open Caregiver burden and proxy-reported outcomes of people without natural speech: a cross-sectional survey study
}

Anna Zinkevich (D) , ' Johanna Sophie Lubasch, ${ }^{1}$ Sarah Anna Katharina Uthoff, ${ }^{1}$ Jens Boenisch, ${ }^{2}$ Stefanie Kalén Sachse, ${ }^{2}$ Tobias Bernasconi, ${ }^{2}$ Lena Ansmann ${ }^{1}$
To cite: Zinkevich A, Lubasch JS, Uthoff SAK, et al. Caregiver burden and proxy-reported outcomes of people without natural speech: a cross-sectional survey study. BMJ Open 2021;11:e048789. doi:10.1136/ bmjopen-2021-048789

- Prepublication history and additional supplemental material for this paper are available online. To view these files, please visit the journal online. (http://dx.doi.org/10.1136/ bmjopen-2021-048789)

Received 06 January 2021 Accepted 28 July 2021
Check for updates

(c) Author(s) (or their employer(s)) 2021. Re-use permitted under CC BY-NC. No commercial re-use. See rights and permissions. Published by BMJ.

${ }^{1}$ Department of Health Services Research, Carl von Ossietzky University of Oldenburg, Oldenburg, Germany

${ }^{2}$ Department of Special

Education and Rehabilitation, University of Cologne, Cologne, Germany

\section{Correspondence to} Anna Zinkevich; anna.zinkevich@uni-oldenburg. de

\section{ABSTRACT}

Objective To examine interrelations between carerelated burden on informal caregivers and their proxy assessments of outcomes in people without natural speech.

Design A cross-sectional survey.

Setting Data were collected in January 2019 from a postal survey of informal caregivers of people without natural speech who are insured by a large regional health insurance company in the German federal state of Lower Saxony.

Participants $n=714$ informal caregivers of people without natural speech of all ages and with various underlying disabilities were identified and contacted via the health insurance company. Data from $n=165$ informal caregivers (26.4\%) were obtained.

Main outcome measures Caregiver burden (selfreported, Burden Scale for Family Caregivers), pragmatic communication skills of people without natural speech (proxy report, self-developed), health-related quality of life of people without natural speech (proxy report, DISABKIDS Chronic Generic Measure - DCGM-12) and functioning of people without natural speech (proxy report, WHO Disability Assessment Schedule 2.0).

Results The analyses revealed significant associations between caregiver burden on the one hand and both proxy-reported health-related quality of life $(b=-0.422$; $p \leq 0.001)$ and functioning $(b=0.521 ; p \leq 0.001)$ on the other. Adding caregiver burden to the regression model leads to a substantial increase in explained variance in functioning ( $R^{2}$ Model $1=0.349 ; R^{2}$ Model $2=0.575$ ) as well as in health-related quality of life ( $R^{2}$ Model $1=0.292 ; R^{2}$ Model $2=0.460$ ).

Conclusions Caregiver burden should be considered an important determinant when informal caregivers report outcomes on behalf of people without natural speech. Longitudinal studies are recommended to better understand the burdens experienced by caregivers when supporting people without natural speech. Trial registration number DRKS00013628.

\section{INTRODUCTION}

Congenital and acquired disabilities are often associated with limitations in using intelligible natural speech. The group of people who use augmentative and alternative communication (AAC) is heterogeneous

\section{STRENGTHS AND LIMITATIONS OF THIS STUDY}

$\Rightarrow$ The heterogeneous sample can be considered as a strength as it reflects reality and highlights the fact that people without natural speech are very diverse in terms of age and underlying disabilities.

$\Rightarrow$ The cross-sectional design considered many confounding characteristics of both informal caregivers and people without natural speech; this can also be seen as a strength.

$\Rightarrow$ The use of proxy measures can be seen as a limitation because of the potential to introduce bias (eg, due to certain personal characteristics, attitudes or experiences of the raters).

$\Rightarrow$ The opportunity to involve people without natural speech in the study design and data collection was limited by the available resources and the lack of appropriate patient-reported outcome measures for people with disabilities and for people without natural speech in particular.

$\Rightarrow$ Due to the high degree of heterogeneity of the sample, the sensitivity and robustness of measures across the full cohort are unclear.

in terms of age, disability and the extent of physical, intellectual and communication limitations. ${ }^{1}$ Data from the UK show that approximately $0.5 \%$ of the British population have complex communication needs and would benefit from AAC. ${ }^{2}$ Furthermore, studies from the USA show that among pupils receiving special education services, $3 \%-12 \%$ have complex communication needs. ${ }^{3}$ It is estimated that worldwide about 97 million people have either severe limitations in using natural speech or no (intelligible) natural speech at all. ${ }^{5}$ For Germany, there are no reliable data on the prevalence of people who use AAC. Aided AAC means the use of communication strategies that involve nonelectronic or electronic devices. Unaided AAC means that the use of communication strategies do not depend on non-electronic or electronic devices, such as sign language, gestures, facial expressions and body movements. We would like to note that we use 
the umbrella terms 'people without natural speech' and 'people who use AAC' when presenting and discussing general aspects of these groups and the term 'people who use aided AAC' when describing the study conducted, as it is the most accurate term to describe the sample of the study conducted.

People who use AAC have diverse support and care needs. ${ }^{3}$ Many individuals use AAC due to multiple disabilities and need extensive support in various areas of life from both professional nursing services and informal caregivers. Due to numerous cultural and sociopolitical differences (even within Europe), no standardised definition of informal care is available. ${ }^{6}$ This study uses a broad definition of informal care. We define informal care as any disability-related care or assistance provided to people with disabilities by a person with a close relationship to them in their private lives (eg, parents, spouses, close relatives or friends).

Informal caregivers take on diverse and often mentally and physically burdensome tasks. ${ }^{7-9}$ Furthermore, informal caregivers of people who use AAC often play a significant role in bearing responsibility for the success of the AAC supply and AAC interventions. The success of the AAC interventions very much depends on the environment and especially on the closest family members and friends. ${ }^{10}$ Usually, informal caregivers are best acquainted with the person's communication and often pass on this knowledge to the person's environment, thereby making a significant contribution to the success of communication in various areas of life. ${ }^{11}$ Other common AAC-related responsibilities include getting technical training in electronic devices or learning sign systems and continuously adapting content to the language development of the person who uses AAC. ${ }^{7}$

Informal caregivers play a central role in AAC studies mainly when it comes to proxy reporting the effects of AAC interventions. ${ }^{12-17}$ However, apart from AAC intervention studies, research rarely addresses the situation and potential care-related burden on informal caregivers of people who use AAC. In a subgroup of people who use AAC, the burden on informal caregivers has been studied in more depth. Bakas et $a l^{18}$ investigated the caregivers' perspective in aphasia and concluded that aphasia does affect caregiver burden. The authors found that informal caregivers of persons with aphasia rate the problems caused by communication limitations as more significant than any other behaviours or tasks in care. There is also evidence that caregivers of stroke patients with aphasia experience occupational loss as well as gaps in cultural and social activities. ${ }^{19}$ Furthermore, informal caregivers of stroke patients are more likely than patients themselves to be affected by depression. ${ }^{20}$

Examining the burden on informal caregivers as proxy respondents is also relevant from a methodological point of view. The conduct of larger surveys of people without natural speech and people who use AAC is characterised by many challenges. ${ }^{21}{ }^{22}$ It is nevertheless possible to include people with profound and multiple learning disabilities who have no speech but who use alternative communication methods to engage with others by using less typical formats ${ }^{23}$ or even using questionnaire-based surveys. ${ }^{24}$ Although an increasing trend towards participatory research designs can be observed, most larger surveys in this area still rely on proxy respondents. One reason for this is likely the fact that there are no tools for patient-reported outcome measures (PROMs) specifically designed for people who use AAC, as Broomfield et $a l^{25}$ found out in their systematic review. On the one hand, it is extremely important to develop such PROMs for people who use AAC, and on the other hand and regarding the current situation, it is also very important to consider potential factors influencing proxy reporting. As shown by studies with caregivers of children with cerebral palsy, one potential factor influencing the proxy assessment of outcomes is the perceived burden of caregiving. ${ }^{26}$ The overall goal of AAC is to facilitate or enable communication in everyday life situations, so pragmatic communication skills can be considered a key outcome of AAC care ${ }^{27}$ Since communication seems to be one of the keys to a better quality of life (QoL) and fewer difficulties in functioning in various life domains, as shown by a study in people with amyotrophic lateral sclerosis (ALS), ${ }^{28}$ the present study focuses on three proxy-reported outcomes. The outcomes include outcomes relevant across disabilities (functioning and health-related quality of life (HRQoL) ) as well as an essential outcome for people who use AAC (communication skills). All three outcomes have been attributed high relevance throughout the International Classification of Functioning, Disability and Health (ICF) and thus in disability research. ${ }^{29}$

\section{AIM AND RESEARCH QUESTION}

This paper aims to explore the role of informal caregiver burden in proxy response surveys of people who use aided AAC. The following research question has been identified: are there interrelations between the subjectively perceived burden on informal caregivers and their proxy assessments of the outcomes of people who use aided AAC?

\section{METHOD}

We used the Strengthening the Reporting of Observational Studies in Epidemiology guidelines for reporting cross-sectional studies. ${ }^{30}$

\section{Participants}

Data were collected in January 2019 from a postal survey of informal caregivers of people who use aided AAC and are insured by a large regional health insurance company in the German federal state of Lower Saxony (over 30\% of the population of Lower Saxony is insured by this health insurance company).

Data were collected within the research project 'New Service Delivery Model for Augmentative and Alternative 
Table 1 Descriptive results: characteristics of informal caregivers

\begin{tabular}{|c|c|c|}
\hline & $\mathbf{n}$ & $\%$ \\
\hline \multicolumn{3}{|l|}{ Age (in years) (missing=4) } \\
\hline$<29$ & 21 & 12.7 \\
\hline 30-39 & 28 & 17 \\
\hline $40-49$ & 44 & 26.7 \\
\hline $50-59$ & 48 & 29.1 \\
\hline $60-69$ & 13 & 7.9 \\
\hline Over 69 & 7 & 4.2 \\
\hline \multicolumn{3}{|l|}{ Sex (missing $=2$ ) } \\
\hline Female & 121 & 73.3 \\
\hline Male & 42 & 25.5 \\
\hline \multicolumn{3}{|l|}{ Employment status (missing $=10$ ) } \\
\hline Employed & 75 & 45.5 \\
\hline Not employed & 80 & 48.5 \\
\hline \multicolumn{3}{|c|}{ Relationship to the person who uses aided AAC (missing=4) } \\
\hline Parents/legal guardians & 122 & 73.9 \\
\hline Other relatives and friends & 39 & 23.6 \\
\hline
\end{tabular}

Communication (AAC) Devices and Intervention' funded by the Federal Joint Committee's Innovation Fund in Germany. The present analysis refers to the historical comparison group (standard care) within this research project and answers an adjunct research question additional to the main project's aim of evaluating the intervention. The research question was considered in the development of the survey instruments. Details on the German AAC and insurance system and the research project design can be found in the published study protocol. $^{31}$

The insurance company identified $\mathrm{n}=714$ persons to be included according to the following inclusion criteria: (a) insured persons of all ages and with all kinds of disabilities and (b) insured persons who had received any kind of aided AAC between 2014 and 2018, financed by the health insurance company. Of the 714 contacted persons, 43 persons were ineligible due to various reasons, for instance, because the insured person was deceased or caregivers did not meet criteria for participation (eg, formal caregivers instead of informal caregivers having answered the survey), and thus were excluded from data analysis. The adjusted gross sample included 671 persons, of whom 506 did not respond after the second contact attempt. The net sample is $\mathrm{n}=165$ participants and the response is $24.6 \%$. Tables 1 and 2 show the characteristics of participating informal caregivers and people who use aided AAC.

Most of the informal caregivers were between 30 years and 59 years $(74.5 \%)$ and women $(74.2 \%)$. Around half of the participants were not employed $(51.6 \%)$, and most of them were parents or legal guardians (75.8\%).
Table 2 Descriptive results: characteristics of people who use aided AAC

\begin{tabular}{lcc}
\hline & $\mathbf{n}$ & $\%$ \\
\hline Age (in years) (missing=2) & 7 & 4.2 \\
\hline $3-6$ & 19 & 11.5 \\
\hline $7-10$ & 34 & 20.6 \\
\hline $11-14$ & 24 & 14.5 \\
\hline $15-19$ & 24 & 14.5 \\
\hline $20-29$ & 16 & 9.7 \\
\hline $30-39$ & 10 & 6.1 \\
\hline $40-49$ & 29 & 17.6 \\
\hline over 49 & & \\
\hline Sex (missing=7) & 63 & 38.2 \\
\hline Female & 95 & 57.6 \\
\hline Male & 97 & \\
\hline Congenital vs acquired disability (missing=11) & \\
\hline Congenital & 58.8 \\
\hline Acquired & 57 & 34.5 \\
\hline Degree of disability & 116 & 9.7 \\
\hline Missing or below 50 & 33 & 20 \\
\hline $50-99$ & & 70.3 \\
\hline 100 & & \\
\hline
\end{tabular}

AAC, augmentative and alternative communication.

People who use aided AAC were predominantly children, adolescents and young adults between 3 years and 29 years $(66.3 \%)$. A total of $90.3 \%$ of the people who use aided AAC had a severe disability (degree of disability of 50 or higher, please see Research Design section). In the sample, $23.7 \%$ have congenital genetic syndromes (eg, Down syndrome), $21.8 \%$ have congenital physical disabilities associated with cerebral movement disorders, and $12.1 \%$ have acquired disabilities or a progressive disease such as craniocerebral trauma or ALS (table 3 ).

To analyse the representativeness of the net sample in terms of age and sex, the data were compared with the data of the 714 contacted potential participants. There were no substantial differences in age or sex between the net sample of 165 included people who use aided AAC and the 714 contacted insured persons. Both the median in the net sample and the median in the sample of 714 contacted persons are in the 15-19 years age group. In the net sample, $38.2 \%$ persons are female; in the sample of 714 contacted persons, $35.9 \%$ persons are female.

\section{Research design}

A cross-sectional observational design was used, which allowed investigation of the interrelations between the informal caregivers' burden and their ratings of the outcomes of people who use aided AAC. The research model is shown in figure 1. 
Table 3 Descriptive results: type of disability

\begin{tabular}{lc}
\hline & $\mathbf{n ~ ( \% )}$ \\
\hline $\begin{array}{l}\text { Congenital physical disabilities associated } \\
\text { with cerebral movement disorders, some of } \\
\text { which are complex }\end{array}$ & $35(21.8)$ \\
\hline Autism spectrum disorders & $16(9.7)$ \\
\hline Specific congenital genetic syndromes & \\
\hline Down syndrome & $13(7.9)$ \\
\hline $\begin{array}{l}\text { Other (eg, Prader-Willi syndrome and } \\
\text { Coffin-Siris syndrome) }\end{array}$ & $23(15.8)$ \\
\hline Acquired disability/progressive disease & $10(6.1)$ \\
\hline $\begin{array}{l}\text { Stroke/intracerebral haemorrhage } \\
\text { Traumatic brain injury }\end{array}$ & $4(2.4)$ \\
\hline Amyotrophic lateral sclerosis & $6(3.6)$ \\
\hline Other & $27(13.9)$ \\
\hline $\begin{array}{l}\text { Non-specific description of the disability } \\
\text { (eg, general developmental disorder) }\end{array}$ & $31(18.8)$ \\
\hline Missing & $165(100)$ \\
\hline Total &
\end{tabular}

We would like to emphasise that the burden collected is a self-assessment by informal caregivers, while all three dependent variables are proxy assessments provided by informal caregivers regarding the outcomes of people who use aided AAC. The bidirectional arrows in the research model highlight the fact that the study design does not aim to investigate causal relationships but rather interrelationships between the independent variable and dependent variables, taking into account confounders. The self-reported burden on informal caregivers caused by supporting or caring for people who use aided AAC is regarded as the independent variable. Three proxy-reported outcomes of people who use aided AAC (pragmatic communication skills, HRQoL and difficulties in functioning) are collected as dependent variables.

Furthermore, data on the following characteristics of informal caregivers (self-reported) were included into the analysis as potential confounders: sex, age group, employment status, relationship to the person who uses aided AAC, education, living situation and first language. As aided AAC often implies the use of technical devices, data on the readiness of informal caregivers to use technology were also collected as a possible confounder. ${ }^{32}$ The following characteristics of people who use aided AAC were collected (proxy reported by caregivers): sex, age group, employment status, congenital versus acquired disability, degree of disability, frequency of use of the AAC device as well as living situation. The construct 'degree of disability' originates from the German system. The disability of a person in Germany is stated in degrees from 20 to 100 , and the degree is assessed in a formal procedure. With a degree of 50 or higher, a person is considered severely disabled. ${ }^{33}$ About $9.4 \%$ of the German population is eligible for this status. ${ }^{34}$

\section{Materials}

The questionnaire includes validated instruments, if available, instruments slightly adapted to the target group after consultation with the original authors as well as selfdeveloped questions (see online supplemental material). All instruments used were checked for comprehensibility and practicability in cognitive pretest interviews $(n=16){ }^{35}$

Informal caregiver burden was measured with the German short version of the Burden Scale for Family Caregivers (BSFC-s; Cronbach's $\alpha=0.92$ ) ${ }^{36}$ Informal caregivers were asked to provide information on their emotional and physical burden using 10 items to be answered on a 4-point Likert scale from 0 strongly disagree to 3 strongly

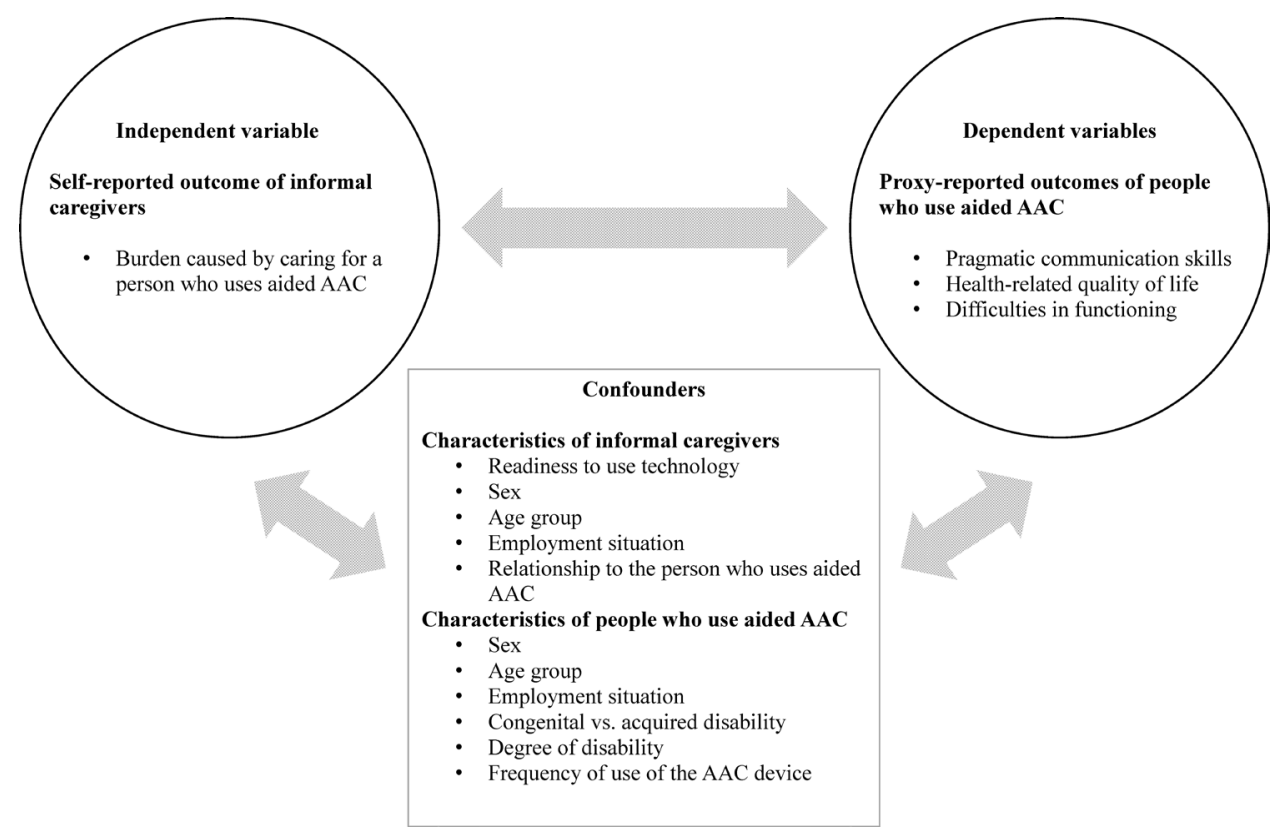

Figure 1 Research model. AAC, augmentative and alternative communication. 
agree. Item scores were added up and divided by the number of items.

To measure pragmatic communication skills, an instrument adapted to the heterogeneous target group of people who use AAC of all ages and with various levels of communication skills was developed. The initial 22-item instrument was based on the communication functions checklist from the 'Communicative Development of Non-speaking Children and their Communication Partners' programme, which is a generic programme developed for all age groups of people who use AAC and their communication partners to enhance 16 communication functions. ${ }^{37}$ Informal caregivers were asked to estimate the pragmatic communication skills of people who use aided AAC on a 5-point scale from 0 very poor to 4 very good. The exploratory factor analysis of the 22-item instrument identified 3 factors. These three groups of items were assigned to three levels on the continuum of communication independence according to Dowden and Cook. ${ }^{38}$ Four items with ambiguous factor loadings were excluded from the scale. The three subscales have the following Cronbach's $\alpha$ values: 0.97 for the 'Independent' subscale (10 items), 0.90 for the 'Transitional Independent' subscale ( 5 items) and 0.87 for the 'Emergent Transitional' subscale (3 items). Since pragmatic communication skills as an overall construct are of importance in the context of the present study, a sum score of 18 items was formed. The fact that the three formed subscales have different numbers of items was taken into account when calculating the sum score. First, three separate sum scores were formed (total score of the subscale divided by the number of items in the subscale). In the next step, the sum scores of three subscales were added and divided by 3. The Cronbach's $\alpha$ of the sum scale is 0.97 .

Due to the lack of an instrument for measuring the HRQoL of both children and adults with disabilities, the German short proxy version of the DISABKIDS Chronic Generic Measure - DCGM-12 questionnaire for children with chronic conditions (Cronbach's $\alpha=0.86$ ) was used. ${ }^{39}{ }^{40}$ The instrument was slightly adapted to the heterogeneous group by replacing the term your child with the generic term the person. Informal caregivers were asked to assess the 10 items on a 5-point scale from 0 never to 4 always. Item scores were added up and divided by the number of items.

The German short proxy version of the WHO Disability Assessment Schedule 2.0 (WHODAS 2.0; Cronbach's $\alpha=0.86$ ) was used to measure difficulties in functioning of people who use aided AAC in six dimensions, including cognition, mobility, self-care, interaction with other people, life activities and participation. ${ }^{41}{ }^{42}$ WHODAS 2.0 is anchored in the theoretical framework of the ICF. It incorporates the functional level of an individual in the most important areas of life and corresponds directly with the ICF dimensions: 'activity' and 'participation'. The instrument has been validated for individuals with severe disabilities ${ }^{43}$ as well as for stroke patients and their relatives. ${ }^{44}$ Informal caregivers assess difficulties in functioning in 6 domains with 12 items on a 5-point scale from 0 none to 4 extreme or cannot do. Consequently, higher scores represent more difficulties. Item scores were added up and divided by the number of items. No statements can be made about the single dimensions since a composite score for all items was formed.

A brief validated 12-item instrument (Cronbach's $\alpha=0.84$ ) was used to measure the confounder 'readiness of informal caregivers to use technology'. ${ }^{32}$

\section{Data collection}

For privacy reasons, the postal survey was sent out by the cooperating health insurance company. The questionnaires together with the corresponding study information were sent to the participants without prior contact. The research team did not receive any personal data on the insured persons or their informal caregivers. If the insured person had a legal representative, this representative was defined as the closest informal caregiver and was addressed directly. If there was no legal representative, the person who uses aided AAC was addressed and asked to pass the questionnaire to their closest informal caregiver. Two weeks after sending the questionnaires, a reminder was sent out, after which we accepted questionnaires for another 4 weeks.

\section{Data analysis}

Initially, all confounders identified as potentially relevant to the research question were tested for multicollinearity. Confounders with strong multicollinearity were excluded from the research model in order to be able to interpret the results as clearly as possible. In a second step, bivariate linear regressions were performed between all dependent variables and the remaining confounders (results are not presented). Confounders were removed from the model if (a) two confounders correlated too strongly when testing multicollinearity or (b) it became apparent when performing the bivariate correlation that certain confounders did not correlate with any of the three dependent variables. After these two steps, the following confounders were excluded from the research model: education, living situation and first language of the informal caregiver as well as living situation of the person who uses aided AAC. Finally, two-step linear regression models were calculated for each of the three outcomes. In the first step (table 4, Model 1), multiple linear regressions with the defined confounders and the dependent variables were performed. In the second step (table 4, Model 2), the independent variable 'caregiver burden' was added to the regression in order to observe the change in explained variance. Missing data were dealt with as follows: Cases were included in the analysis if at least $50 \%$ of total survey items were answered. Cases were included in the analysis if at least $30 \%$ of each single instrument were answered by the respondent. To avoid losing cases due to listwise deletion, dummy variables were created for all categorical variables. IBM SPSS V.22.0 was used for data analysis. 
Table 4 Two-step linear regression models with pragmatic communication skills, difficulties in functioning and health-related quality of life as the dependent variables. Significant results are marked in bold.

\begin{tabular}{|c|c|c|c|c|c|c|}
\hline & \multicolumn{2}{|c|}{ Pragmatic communication skills } & \multicolumn{2}{|c|}{ Difficulties in functioning } & \multicolumn{2}{|c|}{ Health-related quality of life } \\
\hline \multicolumn{7}{|c|}{ Characteristics of informal caregivers } \\
\hline & Model $1 \mathrm{~b}(\mathrm{p})$ & Model 2 b (p) & Model $1 \mathrm{~b}(\mathrm{p})$ & Model 2 b (p) & Model 1 b (p) & Model 2 b (p) \\
\hline $\begin{array}{l}\text { Readiness to use } \\
\text { technology }\end{array}$ & $-0.023(0.858)$ & $-0.005(0.971)$ & $0.070(0.513)$ & $0.191(0.035)$ & $0.126(0.236)$ & $0.033(0.726)$ \\
\hline \multicolumn{7}{|c|}{ Sex (reference category: female) } \\
\hline Male & $-0.326(0.131)$ & $-0.267(0.244)$ & $0.257(0.151)$ & $0.226(0.139)$ & $-0.058(0.746)$ & $-0.052(0.746)$ \\
\hline \multicolumn{7}{|c|}{ Age group (in years; reference category: 40-49) } \\
\hline $0-29$ & $-0.203(0.533)$ & $-0.064(0.859)$ & $-0.071(0.792)$ & $-0.215(0.366)$ & $0.094(0.726)$ & $0.214(0.393)$ \\
\hline 30-39 & $-0.249(0.337)$ & $-0.260(0.340)$ & $-0.193(0.379)$ & $-0.219(0.240)$ & $-0.094(0.668)$ & $0.081(0.683)$ \\
\hline $50-59$ & $-0.142(0.523)$ & $-0.148(0.519)$ & $-0.054(0.775)$ & $-0.155(0.323)$ & $-0.218(0.244)$ & $-0.117(0.480)$ \\
\hline $60-69$ & $-0.735(0.049)$ & $-0.821(0.035)$ & $0.155(0.617)$ & $0.024(0.927)$ & $-0.268(0.386)$ & $-0.156(0.570)$ \\
\hline Over 69 & $0.626(0.160)$ & $0.542(0.239)$ & $-0.317(0.399)$ & $-0.425(0.177)$ & $-0.119(0.751)$ & $0.231(0.487)$ \\
\hline \multicolumn{7}{|c|}{ Employment status (reference category: not employed) } \\
\hline Employed & $-0.020(0.905)$ & $-0.048(0.785)$ & $0.122(0.392)$ & $0.090(0.450)$ & $-0.143(0.314)$ & $-0.125(0.321)$ \\
\hline \multicolumn{7}{|c|}{ Relationship to the person who uses aided AAC (reference category: parents/legal guardians) } \\
\hline $\begin{array}{l}\text { Other relatives and } \\
\text { friends }\end{array}$ & $0.305(0.294)$ & $0.449(0.144)$ & $-0.040(0.870)$ & $0.035(0.868)$ & $-0.131(0.591)$ & $-0.171(0.440)$ \\
\hline \multicolumn{7}{|c|}{ Characteristics of people who use aided AAC } \\
\hline \multicolumn{7}{|c|}{ Sex (reference category: male) } \\
\hline Female & $0.024(0.891)$ & $0.075(0.678)$ & $-0.205(0.158)$ & $-0.259(0.035)$ & $0.047(0.747)$ & $0.101(0.437)$ \\
\hline \multicolumn{7}{|c|}{ Age group (in years; reference category: 15-19) } \\
\hline $0-6$ & $1.134(0.011)$ & $1.227(0.007)$ & $-0.285(0.413)$ & $-0.316(0.274)$ & $0.024(0.945)$ & $0.067(0.826)$ \\
\hline $7-10$ & $0.102(0.741)$ & $0.137(0.667)$ & $-0.002(0.993)$ & $-0.079(0.714)$ & $0.004(0.988)$ & $0.153(0.508)$ \\
\hline $11-14$ & $-0.135(0.628)$ & $-0.147(0.610)$ & $0.305(0.181)$ & $0.194(0.308)$ & $-0.048(0.831)$ & $0.086(0.668)$ \\
\hline $20-29$ & $0.186(0.601)$ & $0.111(0.771)$ & $-0.141(0.635)$ & $0.005(0.986)$ & $0.574(0.054)$ & $0.476(0.081)$ \\
\hline $30-39$ & $-0.188(0.665)$ & $-0.188(0.700)$ & $-0.062(0.867)$ & $-0.170(0.610)$ & $0.651(0.078)$ & $0.672(0.058)$ \\
\hline $40-49$ & $0.256(0.624)$ & $0.227(0.718)$ & $-0.833(0.062)$ & $-0.474(0.267)$ & $1.412(0.002)$ & $1.275(0.005)$ \\
\hline $50-59$ & $0.654(0.181)$ & $0.621(0.236)$ & $-0.280(0.484)$ & $-0.561(0.116)$ & $0.288(0.469)$ & $0.462(0.219)$ \\
\hline Over 59 & $-0.125(0.826)$ & $-0.310(0.603)$ & $-0.192(0.685)$ & $-0.249(0.534)$ & $0.991(0.038)$ & $0.956(0.026)$ \\
\hline \multicolumn{7}{|c|}{ Employment status (reference category: visits an educational institution) } \\
\hline Exclusively at home & $-0.658(0.083)$ & $-0.658(0.112)$ & $0.117(0.703)$ & $-0.146(0.592)$ & $-0.706(0.022)$ & $-0.448(0.121)$ \\
\hline $\begin{array}{l}\text { Working at a social } \\
\text { institution }\end{array}$ & $-0.063(0.847)$ & $-0.040(0.912)$ & $0.475(0.084)$ & $0.406(0.103)$ & $-0.625(0.023)$ & $-0.479(0.069)$ \\
\hline Other employment & $0.118(0.735)$ & $0.149(0.710)$ & $-0.239(0.417)$ & $-0.399(0.141)$ & $-0.277(0.344)$ & $-0.081(0.776)$ \\
\hline \multicolumn{7}{|c|}{ Congenital vs acquired disability (reference category: congenital) } \\
\hline Acquired & $0.308(0.102)$ & $0.319(0.118)$ & $-0.039(0.806)$ & $0.219(0.115)$ & $0.283(0.075)$ & $0.136(0.353)$ \\
\hline \multicolumn{7}{|c|}{ Degree of disability (reference category: 100) } \\
\hline Missing or below 50 & $0.157(0.628)$ & $0.198(0.565)$ & $0.236(0.376)$ & $0.380(0.096)$ & $0.027(0.920)$ & $-0.013(0.956)$ \\
\hline $50-99$ & $-0.015(0.944)$ & $-0.016(0.944)$ & $0.666(\leq 0.001)$ & $0.756(\leq 0.001)$ & $.0042(0.809)$ & $-0.009(0.955)$ \\
\hline \multicolumn{7}{|c|}{ Frequency of use of the AAC device (reference category: $1-10$ times a day) } \\
\hline $\begin{array}{l}\text { Less than } 1 \text { time a } \\
\text { day }\end{array}$ & $0.071(0.756)$ & $0.124(0.625)$ & $0.043(0.823)$ & $0.088(0.607)$ & $0.129(0.508)$ & $0.037(0.838)$ \\
\hline 11-20 times a day & $-0.255(0.253)$ & $-0.281(0.221)$ & $0.087(0.643)$ & $0.153(0.326)$ & $-0.005(0.980)$ & $-0.061(0.709)$ \\
\hline $21-30$ times a day & $-0.272(0.260)$ & $-0.287(0.256)$ & $0.379(0.065)$ & $0.439(0.012)$ & $-0.291(0.153)$ & $-0.376(0.040)$ \\
\hline Over 30 times a day & $-0.225(0.552)$ & $-0.214(0.580)$ & $-0.206(0.520)$ & $-0.128(0.630)$ & $0.274(0.392)$ & $0.210(0.453)$ \\
\hline
\end{tabular}

Independent variable

Continued 
Table 4 Continued

\begin{tabular}{lllllll}
\hline & \multicolumn{2}{l}{ Pragmatic communication skills } & \multicolumn{2}{c}{ Difficulties in functioning } & \multicolumn{2}{c}{ Health-related quality of life } \\
\hline Caregiver burden & - & $0.006(0.958)$ & - & $\mathbf{0 . 5 2 1}(\leq \mathbf{0 . 0 0 1 )}$ & - & $-\mathbf{0 . 4 2 2}(\leq \mathbf{0 . 0 0 1 )}$ \\
\hline $\mathrm{R}^{2}$ & 0.384 & 0.388 & 0.349 & 0.575 & 0.292 & 0.460 \\
$\mathrm{n}$ & 157 & 150 & 162 & 154 & 161 & 153
\end{tabular}

Model 1: with confounders only; model 2: with confounders and informal caregiver burden as independent variable; standardised regression coefficients $(b)$, p values $(p)$, variance explanation $\left(R^{2}\right)$ and sample size per dependent variable $(n)$.

AAC, augmentative and alternative communication.

\section{Patient and public involvement}

Practice partners from the cooperating counselling centres $^{31}$ with a lot of experience working with people who use aided AAC were involved in the planning, recruitment and instrument development of the study via regular meetings. A person who uses aided AAC is part of the team in one cooperating counselling centre and has also provided advice. Despite these aspects, patient involvement in the study design is limited by the available resources.

\section{RESULTS}

The caregiver burden assessed with the BSFC-s instrument revealed a median of 1.1 (mean score $=1.18$; $\mathrm{SD}=0.82 ; \min =0 ; \max =3$ ). The pragmatic communication skills instrument revealed a median of 2.28 (mean score $=2.18 ; \mathrm{SD}=1.00 ; \min =0 ; \max =4)$. The HRQoL instrument showed a median of 3.1 (mean score $=3.08 ; \mathrm{SD}=0.79$; $\min =1$; $\max =4.7$ ). WHODAS 2.0, which measured difficulties in functioning in 6 domains, had a median of 2.36 (mean score $=2.32 ; \mathrm{SD}=0.83 ; \min =0.08 ; \max =4$ ). Detailed results of the two-step linear multiple regression are presented in table 4 .

Significant associations were found between caregiver burden on the one hand and proxy-reported HRQoL $(b=-0.422 ; p \leq 0.001)$ and difficulties in functioning of people who use aided AAC $(b=0.521 ; p \leq 0.001)$ on the other. The directions of the associations show that higher caregiver burden is associated with lower HRQoL and more difficulties in functioning. Adding informal caregiver burden to the regression model in step two leads to a substantial increase in explained variance $\left(R^{2}\right)$ in difficulties in functioning ( $\mathrm{R}^{2}$ Model $1=0.349 ; \mathrm{R}^{2}$ Model $2=0.575)$ as well as in HRQoL $\left(\mathrm{R}^{2}\right.$ Model $1=0.292 ; \mathrm{R}^{2}$ Model 2=0.460). No significant association between informal caregiver burden and pragmatic communication skills has been found.

The following characteristics of people who use aided AAC show significant associations with one or more dependent variables. Female persons who use aided AAC were rated to have less difficulties in functioning than male persons. Significant positive associations between the age of people who use aided AAC and pragmatic communication skills and HRQoL were found. Furthermore, the analyses showed that people who use aided AAC and are exclusively at home or are working at a social institution show significantly lower proxy-reported HRQoL in comparison with people who use aided AAC and attend an educational institution. The analyses also showed that people who use aided AAC and have a degree of disability of 50-99 experience significantly more difficulties in functioning than people who use aided AAC and have a degree of disability of 100 . Compared with people who use aided AAC 1-10 times a day, people who use aided AAC 21-30 times a day have significantly more proxyreported difficulties in functioning and a lower proxyreported HRQoL. In regard to characteristics of informal caregivers, the analyses showed that people who use aided AAC and have a caregiver with higher technology commitment show significantly more difficulties in functioning. Compared with caregivers aged 40-49 years, caregivers aged between 60 years and 69 years report significantly worse pragmatic communication skills of people who use aided AAC. No other characteristics of informal caregivers revealed any significant associations.

\section{DISCUSSION}

This may be the first study to examine the interrelations between caregiver burden and proxy-reported outcomes of people who use aided AAC of all ages and with different conditions. The results show that caregiver burden is negatively related to HRQoL and positively related to difficulties in functioning, but no associations with pragmatic communication skills were found. Below, the found interrelations are discussed against the background of current research in this field. Three explanatory approaches and their combinations can be discussed for the interrelations between caregiver burden and proxy-reported outcomes: 1. Higher caregiver burden leads to worse outcomes.

a. The first explanatory approach assumes that highly burdened caregivers have fewer physical and psychological resources to support their care recipients, for example, by organising opportunities to participate in social activities.

2. Worse outcomes lead to higher caregiver burden.

b. The second explanatory approach is based on the assumption that a significantly higher scope of care and support tasks is usually associated with more severe disability. This can lead to a significantly higher level of care burden being experienced by caregivers of individuals with severe and multiple disabilities who use aided AAC. 
3. Higher caregiver burden leads to more negative reporting.

c. The third explanatory approach is based on the assumption that highly burdened informal caregivers can develop physical and psychological problems. ${ }^{45}$ These persons may assess their shared situation and consequently the outcomes of difficulties in functioning and HRQoL as significantly worse than would caregivers who feel less burdened. In this case, caregiver burden would be seen as a bias that negatively impacts reporting of the outcomes of people who use aided AAC.

These three approaches are discussed below in relation to the outcomes. It should be stressed at this point that there is a large body of research on interrater agreement between self-reports and proxy reports with regard to different patient groups and different health outcomes but hardly any research on the interrelations between caregiver burden and proxy-reported outcomes as examined in this study.

\section{Caregiver burden and $\mathrm{HRQOL}$}

The study revealed that the higher the caregiver burden, the lower the proxy-reported HRQoL of people who use aided AAC. The substantial increase in explained variance $\left(\mathrm{R}^{2}\right)$ in this outcome after adding caregiver burden to the regression model (table 4) indicates that caregiver burden plays an important role in the proxy assessment of HRQoL of people who use aided AAC. Proxy reports on QoL and specifically HRQoL are often used as an orientation for life and care decisions (eg, on the most appropriate residential setting, type of employment or rehabilitative interventions for the person with a disability), although little is known about the aspects that affect these proxy reports. ${ }^{26}$ Davis et $a l^{26}$ showed that parental distress is significantly related to proxy-reported outcomes of children with infantile cerebral palsy. Another study in this research field by White-Koning et $a l^{46}$ who surveyed HRQoL using both the child's self-report and a proxy report, also showed interrelations between the HRQoL of children with cerebral palsy and parental distress. The results show that high parental burden negatively influenced parents' perception and reporting of their child's HRQoL. For the group of people with chronic illness, there are also indications of interrelations between the mental state of their caregivers and proxy-reported QoL. Williams $e t a t^{47}$ found that parental anxiety is significantly associated with the proxy-reported QoL of their children with epilepsy. The results of the studies mentioned above do not clearly support any one of the three explanatory approaches. One of the reasons for this is evidently the cross-sectional character of most studies.

\section{Caregiver burden and difficulties in functioning}

The higher the caregiver burden, the more proxyreported difficulties in functioning are exhibited by people who use aided AAC. The significant increase in explained variance $\left(\mathrm{R}^{2}\right)$ after adding burden on informal caregivers to the regression model (table 4) indicates that caregiver burden also plays an important role in the proxy reporting of difficulties in functioning of people who use aided AAC. To the best of the authors' knowledge, there are no studies that have used the WHODAS 2.0 questionnaire in people who use aided AAC or have investigated factors influencing the proxy assessment of WHODAS 2.0 items. For this reason, two studies are discussed below that examine interrelations between functionality, health status and caregiver burden and provide clues as to which of the three explanatory approaches is most applicable to the findings of the present study.

In a cross-sectional study, Thomas et at $t^{48}$ investigated interrelations between caregiver burden on the one hand and functionality and QoL on the other in people with ALS. The results of the study show that functionality and QoL of people with ALS are negatively correlated with caregiver burden. In the present study, it was shown that difficulties in functioning in people who use aided AAC are positively associated with caregiver burden. The functionality of people with ALS in the study by Thomas et $a l^{48}$ was not assessed by their caregivers but by a neuromuscular specialist using a standardised instrument. As a result, the third explanatory approach mentioned at the beginning (higher caregiver burden leads to more negative reporting) is less likely than the first two. In a large prospective cohort study, Kuzuya et a $t^{49}$ investigated the impact of informal caregiver burden on adverse health outcomes in older care recipients. The authors conclude that high caregiver burden causes poorer health outcomes and thus higher mortality and hospital admissions in older adults, even after considering potential confounding factors. The results of this study speak in favour of the first explanatory approach, which states that higher caregiver burden leads to worse outcomes.

\section{Caregiver burden and pragmatic communication skills}

No interrelation was found between caregiver burden and the proxy-reported pragmatic communication skills of people who use aided AAC. This might be due to the construct of pragmatic communication skills being less abstract and more objective than the constructs of HRQoL and difficulties in functioning. The answers to questions on HRQoL and difficulties in functioning of people who use aided AAC might, therefore, be more strongly influenced by the current physical and psychological well-being of the answering person. The hypothesis is that pragmatic communication skills are more likely to be directly observed and proxy reported by caregivers. The questions on HRQoL and difficulties in functioning offer more scope for interpretation and are, therefore, more sensitive to possible influences that may arise due to caregiver burden. For this reason, a larger sample may be required to identify significant associations between caregiver burden and proxy-reported pragmatic communication skills. To the best of the authors' knowledge, there are no studies that investigate the interrelation between 
caregiver burden and proxy-reported pragmatic communication skills.

\section{Strengths and limitations}

Slight adaptation of some instruments was necessary as the target group is characterised by heterogeneity in age. Furthermore, due to the cross-sectional design of the study, causality of the found interrelations cannot be proven. There is a likelihood that due to the time demands associated with completing the survey, informal caregivers with higher burden were less likely to complete the survey than informal caregivers with lower burden; this could be considered as a limitation. Contacting potential study participants via the health insurance company may also have led to a low response $(26.4 \%)$ because study participants may have had concerns about anonymity. However, the questionnaires were sent back directly to the research team and the health insurance company did not receive any individually identifiable results of the survey. Furthermore, insurants of the cooperating health insurance company tend to have a lower socioeconomic status and a higher demand for healthcare compared with other statutory and private health insurance companies. ${ }^{50}$ However, different health insurance companies have different data structures (eg, for the provision of assistive technology). Therefore, it is common for comparable surveys in Germany to work with only one insurance company and we used the largest health insurance company, covering more than one-third of the population of Lower Saxony.

Finally, as mentioned above, the sample is heterogeneous, which, on the one hand, caused some methodological challenges. On the other hand, the sample reflects reality since people who use aided AAC are very diverse in terms of age and disability-associated limitations.

\section{CONCLUSION}

The study has shown significant interrelations between informal caregiver burden and the outcomes of people who use aided AAC. The presented results are important for the planning, conduct and interpretation of studies in AAC research as well as in disability studies. The results indicate that support services for informal caregivers should not be exclusively AAC related but should take a broad, systemic view of the family's overall domestic situation. When developing interventions, both people who use aided AAC and their informal caregivers should be considered and addressed in order to minimise the carerelated burden. If outcomes of people who use aided AAC are only assessed by means of the proxy ratings of their informal caregivers, it is important to assess the burden on these caregivers and to take this into account when interpreting results and deriving intervention goals. In addition to the views of informal caregivers, the perspective of persons from the environment who are not exposed to any care-related burden (eg, teachers and therapists) might be surveyed.
Longitudinal data are needed to be able to examine the changes in proxy-reported outcomes in caregivers whose burden may change over time. The ideal design would be a prospective study recruiting caregivers in the early stages of the caregiving process. In future studies, subgroups (eg, with regard to the confounder of congenital vs acquired disability) should be examined more closely for differences in terms of burden on informal caregivers. In addition, qualitative studies on the burden on informal caregivers of people who use aided AAC are needed to identify support needs and to develop appropriate support services.

Contributors All members designed the study. AZ drafted all sections of the paper. $A Z$ and JSL performed the statistical analysis. LA revised all sections of the paper and is the guarantor. JSL, SAKU, JB, SKS and TB revised the paper. AZ, SAKU and LA designed the data collection tools, defined the sampling criteria and revised the paper.

Funding The study is funded by the Innovation Fund of the Federal Joint Committee (G-BA), Germany (grant number: 01NVF17019).

Competing interests None declared.

Patient consent for publication Not required.

Ethics approval This study was approved by the Ethics Committee of the Oldenburg Medical School (ID: 2017-137). The investigation was conducted in accordance with the Declaration of Helsinki as amended and the General Data Protection Regulation (EU GDPR).

Provenance and peer review Not commissioned; externally peer reviewed.

Data availability statement Data are available upon reasonable request. The data that support the findings of this study (SPSS dataset) are available from the corresponding author, AZ, upon reasonable request.

Supplemental material This content has been supplied by the author(s). It has not been vetted by BMJ Publishing Group Limited (BMJ) and may not have been peer-reviewed. Any opinions or recommendations discussed are solely those of the author(s) and are not endorsed by BMJ. BMJ disclaims all liability and responsibility arising from any reliance placed on the content. Where the content includes any translated material, BMJ does not warrant the accuracy and reliability of the translations (including but not limited to local regulations, clinical guidelines, terminology, drug names and drug dosages), and is not responsible for any error and/or omissions arising from translation and adaptation or otherwise.

Open access This is an open access article distributed in accordance with the Creative Commons Attribution Non Commercial (CC BY-NC 4.0) license, which permits others to distribute, remix, adapt, build upon this work non-commercially, and license their derivative works on different terms, provided the original work is properly cited, appropriate credit is given, any changes made indicated, and the use is non-commercial. See: http://creativecommons.org/licenses/by-nc/4.0/.

\section{ORCID iD}

Anna Zinkevich http://orcid.org/0000-0002-1049-832X

\section{REFERENCES}

1 Beukelman DR, Mirenda P. Augmentative \& alternative communication: supporting children and adults with complex communication needs. 4th edn. Baltimore: Brookes Publications, 2013.

2 Creer S, Enderby P, Judge S, et al. Prevalence of people who could benefit from augmentative and alternative communication (AAC) in the UK: determining the need. Int $J$ Lang Commun Disord 2016;51:639-53.

3 Binger C, Light J. Demographics of preschoolers who require AAC. Lang Speech Hear Serv Sch 2006;37:200-8

4 Worah S. A survey of Augmentative and alternative communication (AAC) services in Connecticut, 2011. Available: https://ctserc.org/ documents/resources/Augmentative-and-Altenative-Communicationsurvey-2011.pdf [Accessed 8 Dec 2020]. 
5 Light J, McNaughton D, Caron J. New and emerging AAC technology supports for children with complex communication needs and their communication partners: state of the science and future research directions. Augment Altern Commun 2019;35:26-41.

6 Zigante V. Informal care in Europe: exploring formalisation, availability and quality, 2018. Available: https://op.europa.eu/en/publicationdetail/-/publication/96d27995-6dee-11e8-9483-01aa75ed71a1/ language-en [Accessed 8 Dec 2020].

7 Goldbart J, Marshall J. "Pushes and pulls" on the parents of children who use AAC. Augment Alter Commun 2004;20:194-208.

8 Mikolay RM. The challenges and perceptions of raising a child who uses AAC: a review of the literature. Honors research projects. Vol. 233. Akron: University of Akron, 2015.

9 Romano N, Chun RYS. Augmentative and alternative communication use: family and professionals' perceptions of facilitators and barriers. CoDAS 2018;30:1-9.

10 Granlund M, Björck-Akesson E, Wilder J, et al. AAC interventions for children in a family environment: implementing evidence in practice. Augment Altern Commun 2008;24:207-19.

11 Mandak K, Light J. Family-centered services for children with ASD and limited speech: the experiences of parents and speech-language pathologists. J Autism Dev Disord 2018;48:1311-24.

12 Angelo D. Impact of augmentative and alternative communication devices on families. Augment Alter Commun 2000;16:37-47.

13 Broyles LM, Tate JA, Happ MB. Use of augmentative and alternative communication strategies by family members in the intensive care unit. Am J Crit Care 2012;21:e21-32.

14 Bunning K, Gona JK, Newton CR, et al. Caregiver perceptions of children who have complex communication needs following a home-based intervention using augmentative and alternative communication in rural Kenya: an intervention note. Augment Altern Commun 2014;30:344-56.

15 Hines M, Balandin S, Togher L. Communication and AAC in the lives of adults with autism: the stories of their older parents. Augment Altern Commun 2011;27:256-66.

16 McNaughton D, Rackensperger T, Benedek-Wood E, et al. "A child needs to be given a chance to succeed": parents of individuals who use AAC describe the benefits and challenges of learning AAC technologies. Augment Altern Commun 2008;24:43-55.

17 Norburn K, Levin A, Morgan S, et al. A survey of augmentative and alternative communication used in an inner city special school. $\mathrm{Br} \mathrm{J}$ Spl Educat 2016;43:289-306.

18 Bakas T, Kroenke K, Plue LD, et al. Outcomes among family caregivers of aphasic versus nonaphasic stroke survivors. Rehabil Nurs 2006;31:33-42.

19 Kniepmann K, Cupler MH. Occupational changes in caregivers for spouses with stroke and aphasia. Br J Occup Ther 2014;77:10-18.

20 Berg A, Palomäki H, Lönnqvist J, et al. Depression among caregivers of stroke survivors. Stroke 2005;36:639-43.

21 Nind M. Conducting qualitative research with people with learning, communication and other disabilities: methodological challenges, 2008. Available: http://eprints.ncrm.ac.uk/491/1/MethodsReviewPap erNCRM-012.pdf

22 Pullin G, Treviranus J, Patel R, et al. Designing interaction, voice, and inclusion in AAC research. Augment Altern Commun 2017:33:139-48.

23 Harding C, Bukhari S, Hickin J, et al. The People in Control Conference at City University, London: "We have opinions to share about our lives". Tizard Learn Dis Rev 2012;17:169-76.

24 Judge S, Townend G. Perceptions of the design of voice output communication AIDS. Int J Lang Commun Disord 2013;48:366-81.

25 Broomfield K, Harrop D, Judge S, et al. Appraising the quality of tools used to record patient-reported outcomes in users of augmentative and alternative communication (AAC): a systematic review. Qual Life Res 2019;28:2669-83.

26 Davis E, Mackinnon A, Waters E. Parent proxy-reported quality of life for children with cerebral palsy: is it related to parental psychosocial distress? Child Care Health Dev 2012;38:553-60.

27 Light J, McNaughton D. Communicative competence for individuals who require augmentative and alternative communication: a new definition for a new era of communication? Augment Altern Commun 2014;30:1-18.

28 Londral A, Pinto A, Pinto S, et al. Quality of life in amyotrophic lateral sclerosis patients and caregivers: impact of assistive communication from early stages. Muscle Nerve 2015;52:933-41.

29 World Health Organization. International classification of functioning, disability and health, ICF. Geneva: World Health Organization, 2001.
30 von Elm E, Altman DG, Egger M, et al. The strengthening the reporting of observational studies in epidemiology (STROBE) statement: guidelines for reporting observational studies. Ann Intern Med 2007:147:573-7.

31 Zinkevich A, Uthoff SAK, Boenisch J, et al. Complex intervention in augmentative and alternative communication (AAC) care in Germany: a study protocol of an evaluation study with a controlled mixedmethods design. BMJ Open 2019;9:e029469.

32 Neyer FJ, Felber J, Gebhardt C. Entwicklung und Validierung einer Kurzskala zur Erfassung von Technikbereitschaft [Development and validation of a short scale to measure technology readiness]. Diagnostica 2012;58:87-99.

33 Kock M. Disability law in Germany: an overview of employment, education and access rights. German Law J 2004;5:1373-92.

34 Statistisches Bundesamt. Statistics of severely disabled people, 2018. Available: https://www.destatis.de/EN/Themes/SocietyEnvironment/Health/Disabled-People/_node.html [Accessed 8 Dec 2020].

35 Collins D. Pretesting survey instruments: an overview of cognitive methods. Qual Life Res 2003;12:229-38.

36 Graessel E, Berth H, Lichte T, et al. Subjective caregiver burden: validity of the 10-item short version of the burden scale for family caregivers BSFC-s. BMC Geriatr 2014;14:23.

37 Heim M, Jonker V, Veen M, ISAAC. COCP: Ein Interventionsprogramm für nicht sprechende Personen und ihre Kommunikationspartner [COCP: An intervention program for nonspeaking persons and their communication partners]. In: Handbuch Der Unterstützten Kommunikation (01.026.007. Karlsruhe: von Loeper, 2005.

38 Dowden PA, Cook AM. Selection Techniques for Individuals with Motor Impairments. In: Reichle J, Beukelman D, eds. Implementing an augmentative communication system: exemplary strategies for seginning communicators. Baltimore, MD, 2002: 395-432. http:// depts.washington.edu/augcomm/index.htm

39 Bullinger M, Petersen C, Schmidt S. The Disabkids questionnaires: quality of live questionnaires for children with chronic conditions. Lengerich: Pabst Science Publ, 2011.

40 Schmidt S, Debensason D, Mühlan $\mathrm{H}$, et al. The DISABKIDS generic quality of life instrument showed cross-cultural validity. J Clin Epidemiol 2006;59:587-98.

41 Kirchberger I, Braitmayer K, Coenen M, et al. Feasibility and psychometric properties of the German 12-item WHO disability assessment schedule (WHODAS 2.0) in a population-based sample of patients with myocardial infarction from the MONICA/KORA myocardial infarction registry. Popul Health Metr 2014;12:27.

42 Ustün TB, Chatterji S, Kostanjsek N, et al. Developing the World Health Organization disability assessment schedule 2.0. Bull World Health Organ 2010;88:815-23.

43 Tarvonen-Schröder S, Kaljonen A, Laimi K. Comparing functioning in spinal cord injury and in chronic spinal pain with two ICF-based instruments: WHODAS 2.0 and the who minimal generic data set covering functioning and health. Clin Rehabil 2019;33:1241-51.

44 Schlote A, Richter M, Wunderlich MT, et al. WHODAS II with people after stroke and their relatives. Disabil Rehabil 2009;31:855-64.

45 Lach LM, Kohen DE, Garner RE, et al. The health and psychosocial functioning of caregivers of children with neurodevelopmental disorders. Disabil Rehabil 2009;31:741-52.

46 White-Koning M, Arnaud C, Dickinson HO, et al. Determinants of child-parent agreement in quality-of-life reports: a European study of children with cerebral palsy. Pediatrics 2007;120:e804-14

47 Williams J, Steel C, Sharp GB, et al. Parental anxiety and quality of life in children with epilepsy. Epilepsy Behav 2003;4:483-6.

48 Thomas PT, Warrier MG, Sadasivan A, et al. Caregiver burden and quality of life of patients with amyotrophic lateral sclerosis in India. Amyotroph Lateral Scler Frontotemporal Degener 2018;19:606-10.

49 Kuzuya M, Enoki H, Hasegawa J, et al. Impact of caregiver burden on adverse health outcomes in community-dwelling dependent older care recipients. Am J Geriatr Psychiatry 2011;19:382-91.

50 Hoffmann F, Koller D. Verschiedene Regionen, verschiedene Versichertenpopulationen? Soziodemografische und gesundheitsbezogene Unterschiede zwischen Krankenkassen [Different Regions, Differently Insured Populations? Sociodemographic and Health-related Differences Between Insurance Funds]. Gesundheitswesen (Bundesverband der Arzte des Offentlichen Gesundheitsdienstes 2017;79:e1-9. 